\title{
秎 \\ PASTOR NA URNA: O PERFIL DOS SACERDOTES EVANGÉLICOS EM DISPUTA À CÂMARA DOS DEPUTADOS (1998-2018)
}

\author{
PASTOR IN THE URN: THE PROFILE OF THE EVANGELICAL PRIESTS IN \\ DISPUTE TO THE CHAMBER OF MEMBERS (1998-2018)
}

\section{PASTOR EN LA URNA: EL PERFIL DE LOS SACERDOTES EVANGÉLICOS EN DISPUTA A LA CÁMARA DE MIEMBROS (1998-2018)}

Erivelto Amarante ${ }^{1}$

\begin{abstract}
Resumo: O artigo analisa as candidaturas a deputado federal que utilizaram o título de pastor na urna eletrônica entre as eleições de 1998 e 2018 . O objetivo é verificar o perfil social e a preferência partidária dos sacerdotes evangélicos. Trabalhamos com duas hipóteses. A primeira considera que a principal profissão declarada é o próprio sacerdócio e que a maior parte deles não tenha ensino superior. A segunda faz referência a defesa de valores morais conservadores feitas por grande parte desse segmento. Assim, acreditamos que a ideologia predominante seja de direita. Os resultados apontam que a maior parte dos pastores são homens, casados, sem formação superior e com ocupações profissionais alheias ao sacerdócio. A ideologia predominante é de direita, mas os grandes partidos estão perdendo espaço para as pequenas agremiações confessionais e fisiológicas.
\end{abstract}

Palavra-chave: Candidatos pastores; Evangélicos; Eleições; Nome de urna; Preferência partidária.

Abstract: The article analyzes the candidacies for federal deputy that used the title of pastor in the electronic voting machine between the elections of 1998 and 2018. The objective is to verify the social profile and the party preference of these evangelical priests. We work with two hypotheses. The first is that the main profession declared is the priesthood itself and that most of them do not have higher education. The second refers to the defense of conservative moral values made by a large part of this segment. Thus, we believe that the predominant ideology is that of the right. The results show that most of them are men, married, without higher education and with professional occupations outside the priesthood. The predominant ideology is right-wing, but the big parties are losing space to small confessional and physiological groups.

Keywords: Pastors candidates; Evangelicals; Elections; Urn name; Party preference.

Resumen: El artículo analiza las candidaturas a diputado federal que utilizaron el título de pastor en la máquina de votación electrónica entre las elecciones de 1998 y 2018. El objetivo es verificar el perfil social y la preferencia partidaria de estos sacerdotes evangélicos. Trabajamos con dos hipótesis. La primera es que la profesión principal declarada es el sacerdocio en sí y que la mayoría de ellos no tiene estudios superiores. El segundo se refiere a la defensa de los valores morales conservadores realizada por gran parte de este segmento. Así, creemos que la ideología predominante es la de derecha. Los resultados muestran que la mayoría son hombres, casados, sin estudios superiores y con ocupaciones profesionales fuera del sacerdocio. La ideología predominante es de derecha, pero los grandes partidos están perdiendo espacio frente a pequeños grupos confesionales y fisiológicos

Palabras clave: Candidatos pastores; Evangélicos; Elecciones; Nombre de la urna; Preferencia de partido.

\footnotetext{
${ }^{1}$ Doutorando em Ciência Política pela Universidade Federal do Paraná (UFPR), mestre em Comunicação pela UFPR. Bolsista Capes. E-mail: novo.eri@gmail.com. ORCID: 0000-0003-4158-3444
} 


\section{Introdução}

Dados do IBGE revelam que 95\% da população brasileira era católica em 1940. Em 1990, o percentual caiu para 83,3\%; em 2000, para 73,9\%; e, em 2010, para 64,6\%. Enquanto isso, o número de evangélicos só cresceu, saltando nesse intervalo de 50 anos de 2,7\% para 22,2\%. Se o atual ritmo de transição religiosa continuar, as projeções indicam que até 2030 os católicos podem representar menos de $50 \%$ da população e serem ultrapassados pelos evangélicos até 2040 (ALVES et al., 2017, p. 217). Contudo, a presença social desse segmento vai muito além das quatro paredes das igrejas. Sua participação na vida pública transcende os púlpitos e influi cada vez mais na mídia, na cultura e nas instituições políticas (FERNANDES, 1998).

Diversos estudos já abordaram a ascensão dos pentecostais e neopentecostais na política, especialmente no parlamento. Uma das vertentes dedica-se aos perfis das lideranças ocupantes de cargos representativos e da forma de organização das igrejas (ORO, 2003; BORGES, 2007; SILVA, 2016). Outra preocupação envolve os eleitores evangélicos, mapeando suas características sociais, culturais e econômicas (FRESTON, 2008; BOHN, 2004). Um terceiro foco de estudos destina-se a analisar o comportamento das bancadas evangélicas no Congresso (PRANDI; SANTOS, 2017; MACHADO, 2017; QUADROS; MADEIRA, 2018; SILVA, 2012). Também encontramos trabalhos envolvendo a oferta de candidatos (GERARDI, 2016; LACERDA, 2017), como propõe esta pesquisa. No entanto, não encontramos nenhum que analise especificamente o perfil social e a preferência partidária dos pastores, um fenômeno cada vez mais presente nas eleições.

Silva (2015) identificou na generalidade as principais nomenclaturas com referência religiosa utilizadas por candidatos a deputado federal e estadual e constatou que o título de pastor concentrou 61,2\% dos casos em 2014. Esse movimento também é observado em outras disputas. Dados do TSE referentes à eleição municipal de 2020 somaram o registro de 8,7 mil concorrentes com títulos religiosos. Destes, 4,4 mil traziam o nome de pastor na urna, representando $51 \%$ do total. Diante desse contexto, este trabalho tem o objetivo de mapear o perfil social e a preferência partidária dos candidatos ao cargo de deputado federal que utilizaram o nome de pastor na urna entre 1998 e 2018.

Para a pesquisa empírica, trabalhamos com duas hipóteses. A primeira está relacionada com o perfil social dos candidatos. Neste caso, (H1) esperamos que a principal profissão declarada é o próprio sacerdócio e que a maior parte deles não tenha ensino superior, uma vez que o processo de formação de um pastor não requer graduação em algumas denominações. A segunda hipótese trata da preferência partidária. Conforme a literatura (GONÇALVES, 2011; MACHADO, 2017; SANTOS, 2020), o segmento evangélico tem por hábito a defesa de pautas morais conservadoras. Assim, (H2) acreditamos que a maioria dos pastores sejam recrutados por partidos de direita e que as candidaturas se pulverizem por diferentes legendas devido a fragmentação partidária e das denominações evangélicas. 
Com o propósito de testar nossas hipóteses, utilizamos dados eleitorais do TSE aplicados ao modelo do Observatório das Elites Sociais e Políticas do Brasil (UFPR) e a tipologia dos partidos proposta por Codato, Berlatto e Bolognesi (2018). Antes, abordamos com mais detalhes a ascensão dos evangélicos na política, a relação dos partidos brasileiros com as instituições religiosas, especialmente as legendas confessionais comandadas pela Igreja Universal do Reino de Deus (IURD) e a Igreja Assembleia de Deus (IAD), e o uso do nome de urna para identificação dos candidatos. Por fim, apresentamos os dados e analisamos os resultados da pesquisa.

\section{Entre Deus e a política}

A presença dos evangélicos na política brasileira era residual até a segunda metade dos anos 1980. Os pentecostais conseguiram eleger seu primeiro representante no parlamento nacional em 1963 (CAMPOS, 2005). O pastor Levi Tavares, da Igreja Brasil para Cristo, ocupou uma cadeira de deputado federal por São Paulo, sendo eleito pelo Partido Social Democrático (PSD), extinto na ditadura militar. Contudo, Freston (1999) observa que a Assembleia Constituinte (AC), formada em 1987, marcou uma nova era para os evangélicos no poder político. Na ocasião, eles elegeram um total de 32 constituintes, 18 deles pentecostais. Esse grupo também era formado por alguns parlamentares de esquerda, como Benedita da Silva e Lysânias Dias Maciel. Mas é a partir da década de 1990 que os pentecostais ganham força.

Para Campos (2005), a ascensão evangélica na política foi possível graças ao contexto de alastramento da presença pentecostal e neopentecostal, que permitiu aos seus membros "saírem do território marginalizado em que se situavam, para assumir uma atuação mais sistemática e calculada no panorama político" (CAMPOS, 2005, p.7). Ele ressalta que uma das maiores evidências dessa expansão é a bancada evangélica. Em 2003, o grupo foi oficializado como Frente Parlamentar Evangélica (FPE) e é formado por representantes de diferentes partidos com o objetivo de atuar de forma organizada no Congresso.

Segundo Prandi e Santos (2017, p. 187), a FPE "não é política nem ideologicamente homogênea, mas é, de forma geral, conservadora". Nesse sentido, a atuação da bancada "traz para a luta política demandas moralistas que são reivindicações reais dos setores populares, não habituados a separar as esferas da política e da moralidade privada" (PRANDI; SANTOS, 2017, p. 187). Já Gonçalves (2011) entende que "não existe uma bancada evangélica, ou seja, algo que oriente estes deputados a votarem em bloco" (GONÇALVES, 2011, p. 198). Fato é que o grupo começa a ganhar corpo em 1994, quando 32 deputados federais evangélicos foram eleitos. Em 1998, o número chegou a 49, e, em 2002, saltou para 68.

O crescimento do bloco foi freado após sucessivos escândalos de corrupção envolverem parlamentares evangélicos. Em 2005, o "Mensalão" atingiu a base de apoio do governo Lula na Câmara e teve grande repercussão na mídia. Entre os envolvidos estavam nomes da FPE, como os deputados Bispo Carlos Rodrigues (PL-RJ) e Wanderval Santos (PL-SP), ambos da IURD. Em 
2006, a Polícia Federal deflagrou a Operação Sanguessuga, contra um esquema de fraudes em licitações na Saúde. Uma CPMI foi criada no Congresso e revelou o envolvimento de 72 deputados federais. Destes, 28 eram evangélicos. Por conta do desgaste, a bancada reduziu pela metade, com 30 nomes. Em 2010, a FPE se reergueu com a eleição de 63 parlamentares. Desde então, não parou mais de crescer. Em 2014, foram 74, e em 2018, 91.

A literatura vem tentando encontrar respostas desde a década de 1990 sobre o tipo e o grau de apoio que esse grupo obtém dos fiéis e como esse comportamento se materializa em votos. Alguns trabalhos apontam para a existência de relações clientelistas entre a igreja e seus membros. Para Machado (2015), os fiéis e eleitores da IURD fazem parte da sua "clientela política" (MACHADO, 2015, p. 95). Sousa (2009) acredita que os projetos assistenciais da Igreja Universal "propiciam um clientelismo de novo tipo - institucionalizado e religiosamente legitimado - servindo de trampolim político para lideranças emergentes da igreja" (SANTOS, 2009, p. 14).

\section{Representação partidária}

Malfatti (2017) identificou três condições necessárias para o surgimento dos partidos cristãos. A primeira delas é a própria democracia, ou seja, a existência de um regime representativo e de um parlamento. A segunda demanda que o Estado deve ser neutro do ponto de visto religioso, já que não faria sentido um partido cristão onde a Igreja já fizesse parte do aparato estatal. Por fim, a última condição é a de que os grupos religiosos constituam uma minoria politicamente ou que haja um partido que os discriminem. "Foi o que aconteceu no período, mormente no século XIX, em que os católicos, na Itália, haviam perdido espaço para os liberais e, por isso, era necessário reconquistar seu lugar” (MALFATTI, 2017, p. 3).

Panebianco (2005) propõe a análise dos partidos a partir da distribuição de poder. No seu entendimento, essas agremiações podem percorrer caminhos diferentes com o mesmo estágio institucional. Para ele, o que importa não é a estrutura hierárquica, como Duverger (1980), mas olhar para quem controla e o que controla no interior do partido. Um dos três fatores que constitui o modelo genético trata justamente do patrocínio do partido por uma instituição externa, como uma igreja. Esse apoio é o que define a sua legitimação. Nesse sentido, a Igreja Universal desempenha um papel central no processo eleitoral de seu partido, o Republicanos. Fonseca (1996) afirma que o Conselho de Bispos é o responsável por estipular a distribuição geográfica dos candidatos e fornecer estrutura midiática e assistencialista para promover seus nomes.

Segundo Oro (2003), o processo de organização política da IURD passa pela realização de recenseamentos de seus fiéis antes das eleições, tendo como objetivo saber com precisão o número de potenciais eleitores de que dispõe. Os dados são posteriormente encaminhados à liderança nacional para avaliar quantos candidatos deve lançar em cada região. Para Silva (2015), esse modelo busca evitar uma competição interna, para que "candidatos iurdianos" não tenham 
que competir pelos mesmos votos, aumentando as chances de sucesso eleitoral (SILVA, 2015, p. 7).

O modelo bem-sucedido da Universal levou a Igreja Assembleia de Deus a adotar algumas de suas estratégias, como a indicação de candidaturas oficiais e o comando de um partido através do PEN (Partido Ecológico Nacional), rebatizado para Patriota em 2018. Contudo, a igreja aceita candidatos de diferentes partidos. Ao contrário da IURD, o processo de escolha é descentralizado e não está subordinado a uma única instância. O recrutamento da IAD permite a apresentação voluntária de nomes de qualquer membro da igreja. Após a triagem, os précandidatos são submetidos a votação no colégio eleitoral de pastores e obreiros, que então encaminha uma lista reduzida de nomes para as prévias.

Otto Kirchheimer (2012) estudou os sistemas partidários modernos e destaca que os partidos confessionais conseguiram preencher tanto a função de integração social na era industrial como a integração política no próprio sistema partidário. Contudo, ele ressalta que a "natureza confessional deu-lhes uma força de caráter que restringiu seriamente seu crescimento potencial" (KIRCHHEIMER, 2012, p. 360). No contexto brasileiro, esses partidos atuam como satélites de partidos maiores de direita ou são fisiológicos, compondo a base de apoio de governos de qualquer ideologia.

Coppedge (1997) propôs no final da década de 1990, uma nova ordenação dos sistemas de partidos latino-americanos a partir de uma análise que considera a atuação dos blocos ideológicos de forma mais completa e mais complexa. O modelo observa duas dimensões simultaneamente, sendo que a primeira foca na oposição entre "confessional" e "secular", e a segunda na dimensão clássica "esquerda-direita", incluindo subdivisões entre centro-direita, centro e centro-esquerda. A combinação das duas dimensões permite analisar uma série de categorias diferentes. Do ponto de vista religioso, transita da direita cristã até a esquerda secular tradicional.

Codato, Berlatto e Bolognesi (2018) aplicaram o conceito de Coppedge para definir uma tipologia para os partidos políticos brasileiros. Nessa classificação, os partidos confessionais de direita seriam os democratas-cristãos, definidos como aqueles que "baseiam a sua ideologia ou programa explicitamente em concepções religiosas e/ou estão ligados a igrejas e a movimentos com forte apelo conservador", como "pró-vida" ou "pró-família” (CODATO et al. 2018, p. 879). Além do Republicanos, da IURD, e do Patriota, da Assembleia de Deus, também fazem parte desse grupo o Partido Social Cristão (PSC); o Partido Liberal (PL), conhecido por Partido da República (PR) até 2019; e o Democracia Cristã (DC), antigo Partido Social Democrata Cristão (PSDC). 


\section{Nome de urna}

No Brasil, o nome de urna foi estabelecido pela Lei 9.504/1997, em seu Artigo 12, e, posteriormente, regulamentada pelo TSE na Resolução no 23.455, de 15 de dezembro de 2015, que dispõe sobre a escolha e o registro dos candidatos nas eleições. $\mathrm{O}$ artigo 31 define que o nome indicado "terá no máximo trinta caracteres, incluindo-se o espaço entre os nomes, podendo ser o prenome, sobrenome, cognome, nome abreviado, apelido ou nome pelo qual o candidato é mais conhecido". A condicionante é que "não se estabeleça dúvida quanto a sua identidade, não atente contra o pudor e não seja ridículo ou irreverente" (BRASIL, 2015, p. 10). Fora isso, os candidatos têm liberdade de escolha do nome de urna diferente do nome civil.

Os estudos sobre o nome de urna são escassos na literatura e normalmente são explorados pelo campo da linguística. Nessa perspectiva, autores como Amaral e Machado (2015) e Soares (2017) fazem uso de tipologias antroponímicas para entender o nome usado pelos candidatos. Contudo, Santos e Rocha (2020) buscam fazer uma aproximação da linguística com a Ciência Política ao analisar a relação entre os nomes e o voto. Elas concluíram que o título serve como uma "espécie de atalho cognitivo e que, de certa forma, compensaria a falta de conhecimento do eleitor sobre a política" (SANTOS; ROCHA, 2020, p. 15). Para Boas (2014) os nomes de urna agregam ideologias e categorias sociais e servem de mecanismo para associações por grupos e estereótipos.

Rocha e Santos (2019) ressaltam que nas eleições municipais de 2016 houve um crescimento de $25 \%$ no uso do título de "pastor" ou "pastora" nas urnas em relação a 2012. Além disso, também foram encontradas variações como "pastorzinho" e "pastorzão". Elas afirmam que termos religiosos podem ser adicionados pelos candidatos com intuito de angariar votos entre cristãos, mas que ao contrário de outras insígnias, também podem dividir os eleitores. "Identificarse como padre, por exemplo, pode contribuir para conseguir votos de católicos, mas não de evangélicos" (ROCHA; SANTOS, 2019, p. 76). Por sua vez, títulos como "médico" e "professor" são mais abrangentes e buscam associar um estereótipo positivo, como alguém inteligente, competente e que cuida das pessoas.

Gerardi (2016) pesquisou as designações eclesiásticas de candidatos a deputado federal entre as eleições de 1998 e 2014 e constatou que a insígnia de pastor concentra a maioria dos casos, perfazendo uma média de 64,6\% no período. Em segundo lugar vem o título de irmão, com $17 \%$ dos registros. Em relação aos eleitos, a proporção de pastores é ainda maior, atingindo 70,4\% do total (GERARDI, 2016, p. 14). Em 2018, o deputado federal que mais recebeu votos com o título de pastor na urna foi Marco Feliciano. Ligado à igreja Assembleia de Deus, ele foi reeleito por São Paulo com 234.281 votos, sendo o nono mais votado do país. 


\section{Métodos}

$\mathrm{Na}$ literatura, encontramos pesquisas que fazem o levantamento dos títulos religiosos usados em candidaturas (GERARDI, 2016; SILVA, 2015). No entanto, nenhuma delas detalha especificamente o perfil social e a preferência partidária dos pastores. Este estudo tem o objetivo de suprir essa lacuna ao analisar a participação dos sacerdotes evangélicos nas eleições para a Câmara dos Deputados entre 1998 e 2018. A coleta faz uso dos bancos de dados eleitorais do TSE. Para a análise, aplicamos a codificação do Observatório das Elites Sociais e Políticas do Brasil (UFPR) e a tipificação proposta por Codato, Berlatto e Bolognesi (2018).

Santos (2020), ao citar a tipificação proposta pelos três autores, destaca a importância de subdividir os partidos como uma forma de verificar o crescimento da direita nas últimas eleições, especialmente na Câmara dos Deputados. Ao tratar dos políticos evangélicos, ela pondera que através dessas categorias é possível verificar qual vertente ideológica tem sustentado a ascensão dos pentecostais e neopentecostais no país. A autora também acredita que a classificação permite estimar a direção e entender o significado por trás do crescimento dos evangélicos na representação política brasileira.

A identificação dos pastores deu-se exclusivamente pelo título usado nos nomes de urna. Houve o cuidado para que não fossem incluídos na lista sobrenomes sem relação com a posição eclesiástica ${ }^{2}$. Optamos por estudar aqui apenas o perfil dos candidatos que utilizaram a denominação de pastor para a identificação eleitoral. Com isso, nossa intenção é captar o fenômeno das candidaturas que associam o nome civil ao status evangélico e contribuir para as pesquisas que fazem uso do nome de urna como objeto de estudo. Isto posto, apresentamos a seguir os resultados.

\section{Resultados}

A primeira categoria traz dados gerais sobre o perfil dos candidatos analisados. A diferença de gênero chama atenção. Em 1998, nenhuma pastora foi candidata. Nas eleições seguintes, elas até apareceram, mas em proporção bem menor que os homens. Em 2018, ano do maior número de candidaturas femininas, as pastoras ocuparam 16\% do total, com 15 nomes. Já os pastores somaram $84 \%$ do recorte, com 79 nomes. Defensores do modelo de família tradicional, ao olharmos as informações sobre o estado civil desses sacerdotes não encontramos nenhuma surpresa. Ao todo, $89,8 \%$ se declararam casados, contra 3,5\% de divorciados e $1,2 \%$ de separados judicialmente. Os solteiros não passam de 3,2\% e os viúvos, 1,2\%.

Ao filtrar os pastores da nossa amostra pelo nome da urna e não pela profissão, podemos verificar quais outras ocupações eles desempenham. Conforme o Gráfico 1, embora a maior parte deles tenham declarado que o sacerdócio é o principal ofício, esse índice alcançou apenas $27,7 \%$

\footnotetext{
${ }^{2}$ A codificação está disponível para consulta em: https://bit.ly/CandPr. Acesso em: 15 mai. 2021.
} 
do corpus. Portanto, a maioria exerce outras atribuições ou depende de outras fontes de renda. Ao todo, $10 \%$ se declararam políticos profissionais. A proporção de trabalhadores assalariados foi de 8,8\%, contra 4,8\% de empresários. Os funcionários públicos somaram 4\%, mesmo percentual dos advogados. Em nossa codificação, optamos por agrupar algumas profissões. Os demais profissionais liberais, que perfazem $8,8 \%$ do total, incluem funções como administrador, contador e jornalista.

Gráfico 1 - Candidatos pastores por profissão (1998-2018)

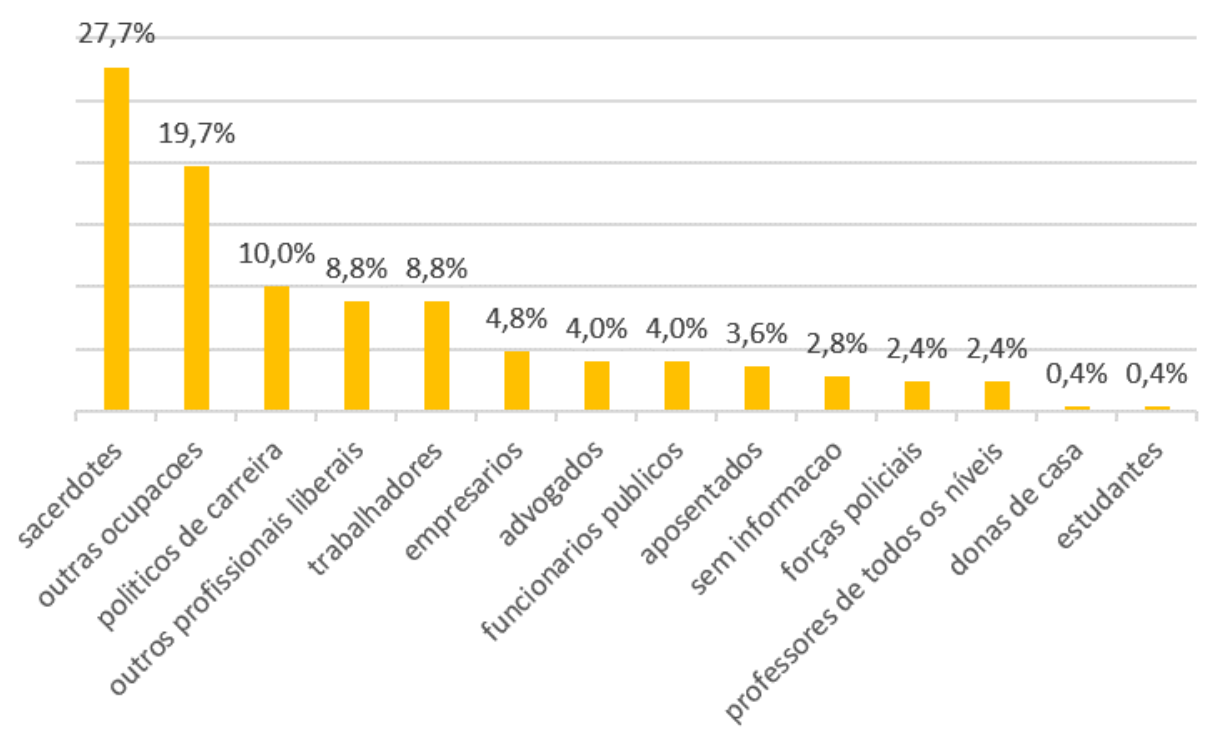

Fonte: Elaboração própria com base em dados do TSE.

Embora as forças policiais representem apenas 2,4\% do total de ocupações, o grupo que inclui candidatos das forças repressivas do Estado é outro segmento que vem aumentando a cada eleição. Assim como os pastores, os militares costumam associar a insígnia funcional ao nome civil na urna eletrônica. Outra semelhança que comungam está relacionada com a defesa de pautas conservadoras em termos de costumes (BERLATTO; CODATO; BOLOGNESI, 2016). Alguns candidatos optaram por associar o título religioso e militar, como "Pastor Sargento Isidório" e "Pastor Juvenal Bombeiro". Os professores registram o mesmo índice. Assim como os militares, também encontramos nomes de urna com os dois títulos profissionais, como "Professor Pastor Cordeiro".

Um dos motivos para a perda de católicos é a escassez de padres. Uma das razões é o tempo de formação exigido. O processo demanda oito anos de estudo em período integral e inclui duas graduações (filosofia e teologia). Por sua vez, a formação de um pastor pode nem existir formalmente. As etapas variam conforme a denominação. Os neopentecostais, como Deus é Amor e IURD, seguem o discipulado hierárquico, onde os mais experientes transmitem o conhecimento aos que estão abaixo. 
Gráfico 2 - Candidatos pastores por escolaridade (1998-2018)

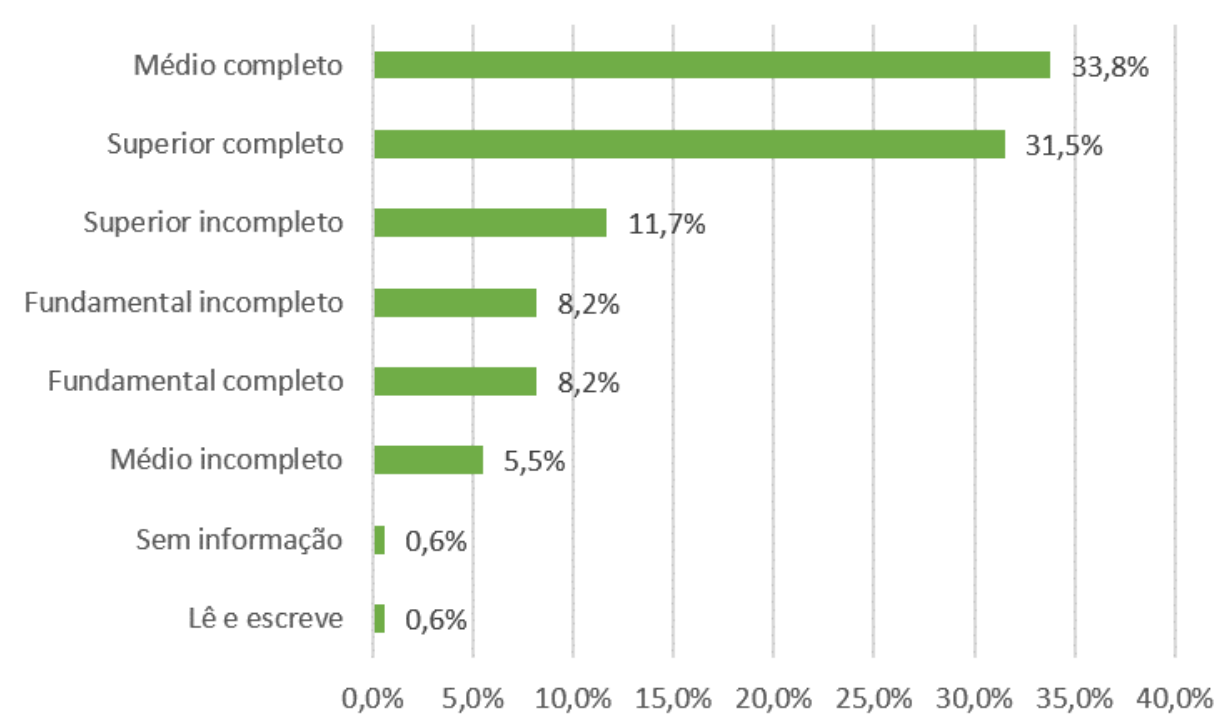

Fonte: Elaboração própria com base em dados do TSE.

Ao analisarmos a escolaridade dos candidatos autodenominados pastores na urna, constatamos que 31,5\% deles concluíram o ensino superior. O Gráfico 2 também mostra que outros $11,7 \%$, não terminaram a graduação. Portanto, a maior parte deles têm apenas o ensino básico. O ensino médio completo lidera a lista, com 33,8\%. Por outro lado, 5,5\% disseram não ter concluído essa etapa. Já o ensino fundamental completo e incompleto registrou 8,2\% cada. Contudo, $0,6 \%$ declarou que apenas lê e escreve.

Para testar a nossa segunda hipótese, analisamos o perfil partidário dos pastores que lançaram suas candidaturas para deputado federal entre 1998 e 2018. Quando verificamos a classificação por bloco ideológico, percebemos que a grande maioria desses sacerdotes evangélicos estão filiados em legendas à direita do espectro político, totalizando uma média de $77,3 \%$ nas seis eleições mencionadas. O total de inscritos em partidos de centro e esquerda somam os mesmos $11,3 \%$ cada.

Ao observamos no Gráfico 3 a evolução nos últimos 20 anos, percebemos que os partidos de direita permaneceram muito à frente dos demais em todas as eleições. Apenas em 1998 essa diferença foi menor, mas por conta do pequeno número de concorrentes. Já os blocos reunindo os partidos de centro e esquerda pouco oscilaram na parte de baixo. Contudo, essa classificação é demasiada agregada e não revela muitas informações para além do protagonismo da direita. Existem outras variáveis institucionais e sociais envolvidas que precisam ser consideradas. 
Gráfico 3 - Candidatos pastores por bloco ideológico (1998-2018)

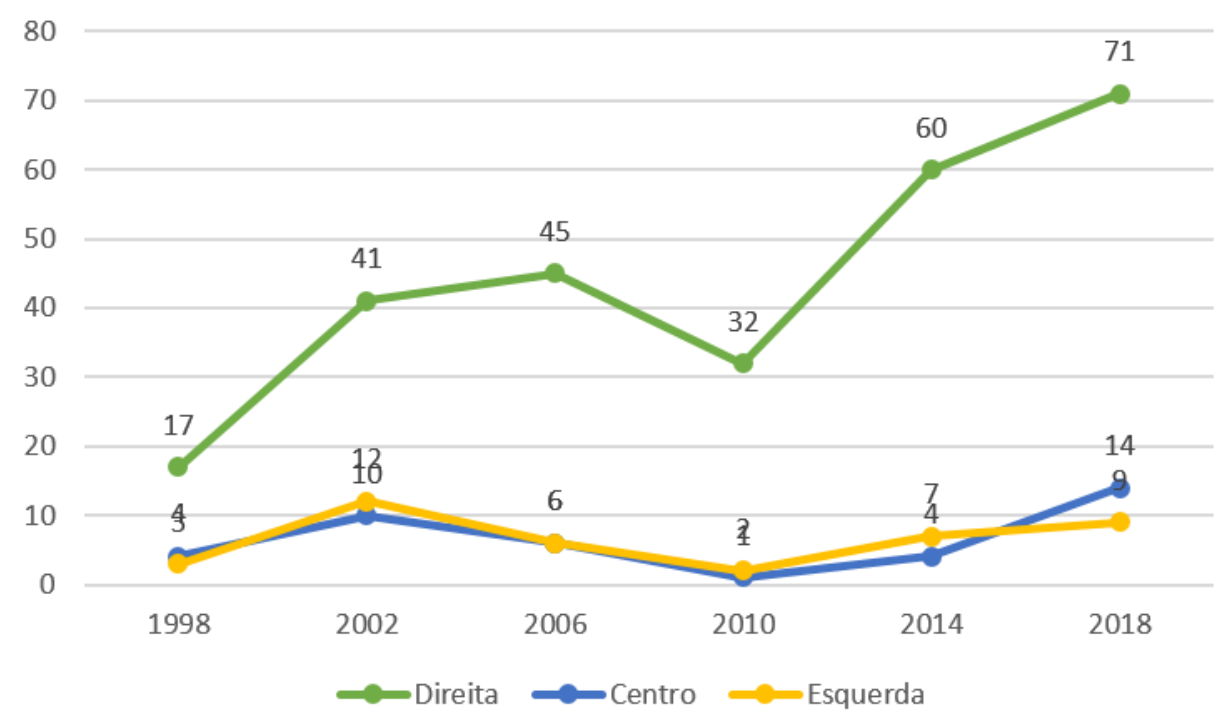

Fonte: Elaboração própria com base em dados do TSE.

Embora a maioria desses candidatos tenham procurado partidos de direita para concorrer a uma vaga de deputado federal, essa direita não se manteve estática ao longo do período. Pelo contrário, ela moveu-se conforme as circunstâncias políticas, o que alterou preferências, relevância e oportunidades eleitorais. Por isso, olhamos agora para o tamanho de cada partido e a sua ideologia.

Podemos ver no Gráfico 4, a ascendência dos pequenos partidos de direita entre as candidaturas de pastor. Nesse grupo estão incluídas legendas como o PSC e o PTC, que reúnem uma grande quantidade de sacerdotes. Também é nítido o declínio dos grandes de direita, como o PP e o PFL/DEM. Os pequenos fisiológicos ultrapassaram nas últimas duas eleições esse bloco. Até mesmo os grandes de esquerda, como PSB e PDT, superam a direita tradicional. Portanto, observamos uma mudança no recrutamento, com os pastores migrando gradativamente para os pequenos partidos e legendas fisiológicas.

Também calculamos a posição ideológica dos partidos usando a ordenação de Coppedge (1997) para a América Latina. Adotamos aqui a categorização de Codato, Berlatto e Bolognesi (2018) que emprega seis das 13 possibilidades deste modelo. São elas: partidos confessionais de direita, baseados em doutrinas religiosas; partidos personalistas, que apelam ao carisma e autoridade de um líder; seculares de centro, com programas vagos e liberais na economia; seculares de centro-esquerda, que defendem políticas sociais; seculares de esquerda, de retórica marxista; e seculares de direita, conservador nos costumes. 
Gráfico 4 - Candidatos pastores por tamanho dos partidos (1998-2018)

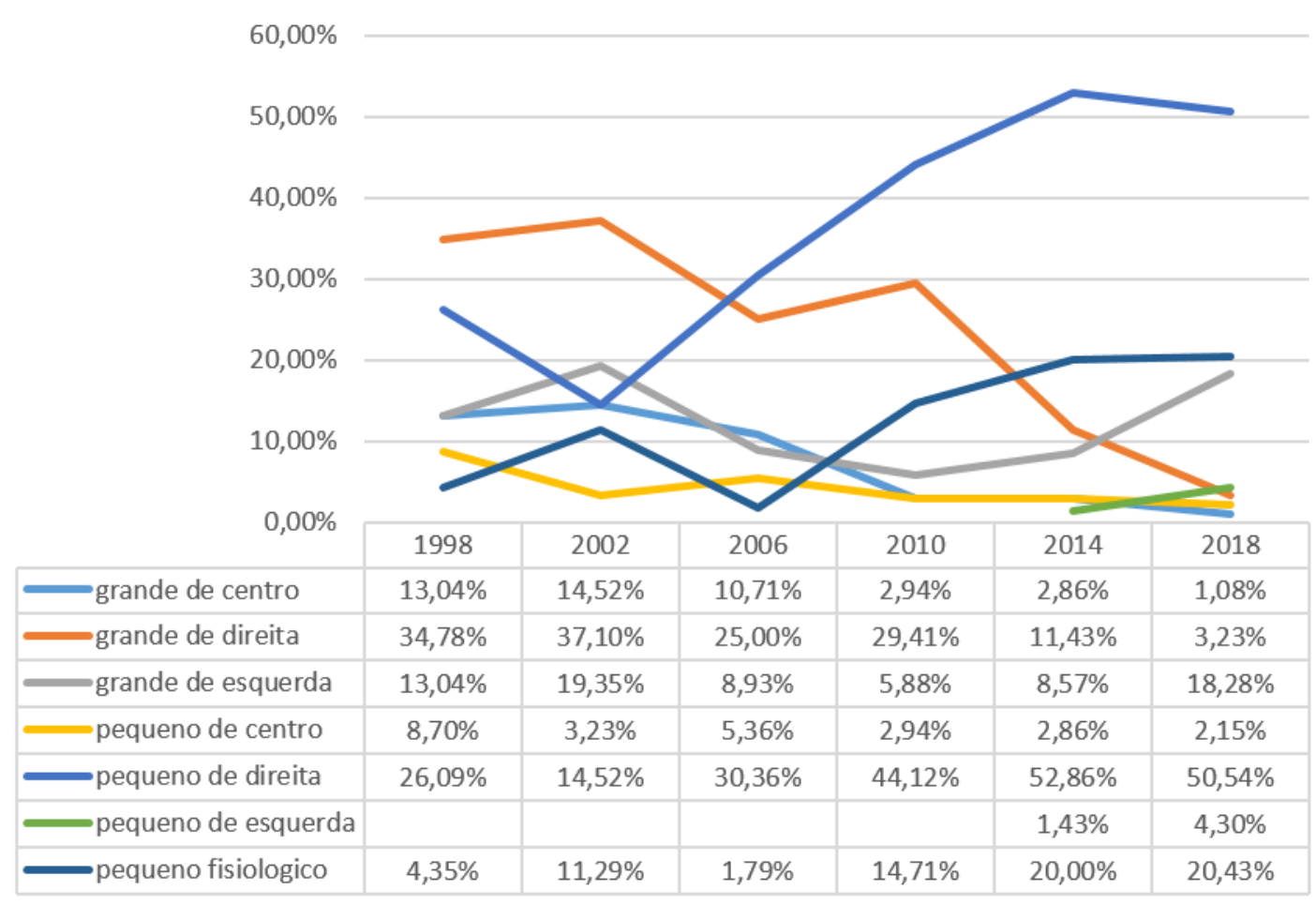

Fonte: Elaboração própria com base Codato et al. (2018) e TSE.

Ao aplicarmos as variáveis acima, constatamos no Gráfico 5 que os partidos confessionais assumiram a liderança na preferência dos candidatos pastores. Logo em seguida aparece os personalistas, que lideram a somatória de todas as eleições, com 28,9\%. Esse conjunto reúne siglas que atuam em função de interesses pessoais e políticos dos seus dirigentes. Também nessa categoria, percebemos o declínio das legendas seculares de direita nos últimos pleitos. $\mathrm{O}$ mesmo ocorreu com as agremiações seculares de centro. Num patamar bem abaixo, complementam a lista os seculares de esquerda e de centro-esquerda, que pouco oscilaram na última década.

Em relação ao quadro geral de partidos. O PSC foi a legenda que mais lançou candidatos para deputado federal com o título de pastor na urna. Entre 1998 e 2018, acumulou 11,6\% do total. A sigla é liderada pelo Pastor Everaldo Pereira, da Assembleia de Deus. Em seguida, aparece o PTB, com 7,3\%; o PTC, com 5,5\%; e o PHS (incorporado ao Podemos em 2019), com 4,7\%. O PRB (atual Republicanos), da Igreja Universal, aparece em quinto lugar, com 4,7\% de candidaturas. O PSB é o partido mais à esquerda do espectro político com o maior número de nomes, com 4,7\%, uma posição acima do PL e do MDB, ambos com 4,1\%. O PT lançou apenas dois nomes no período. 
Gráfico 5 - Candidatos pastores por ideologia de Coppedge (1998-2018)

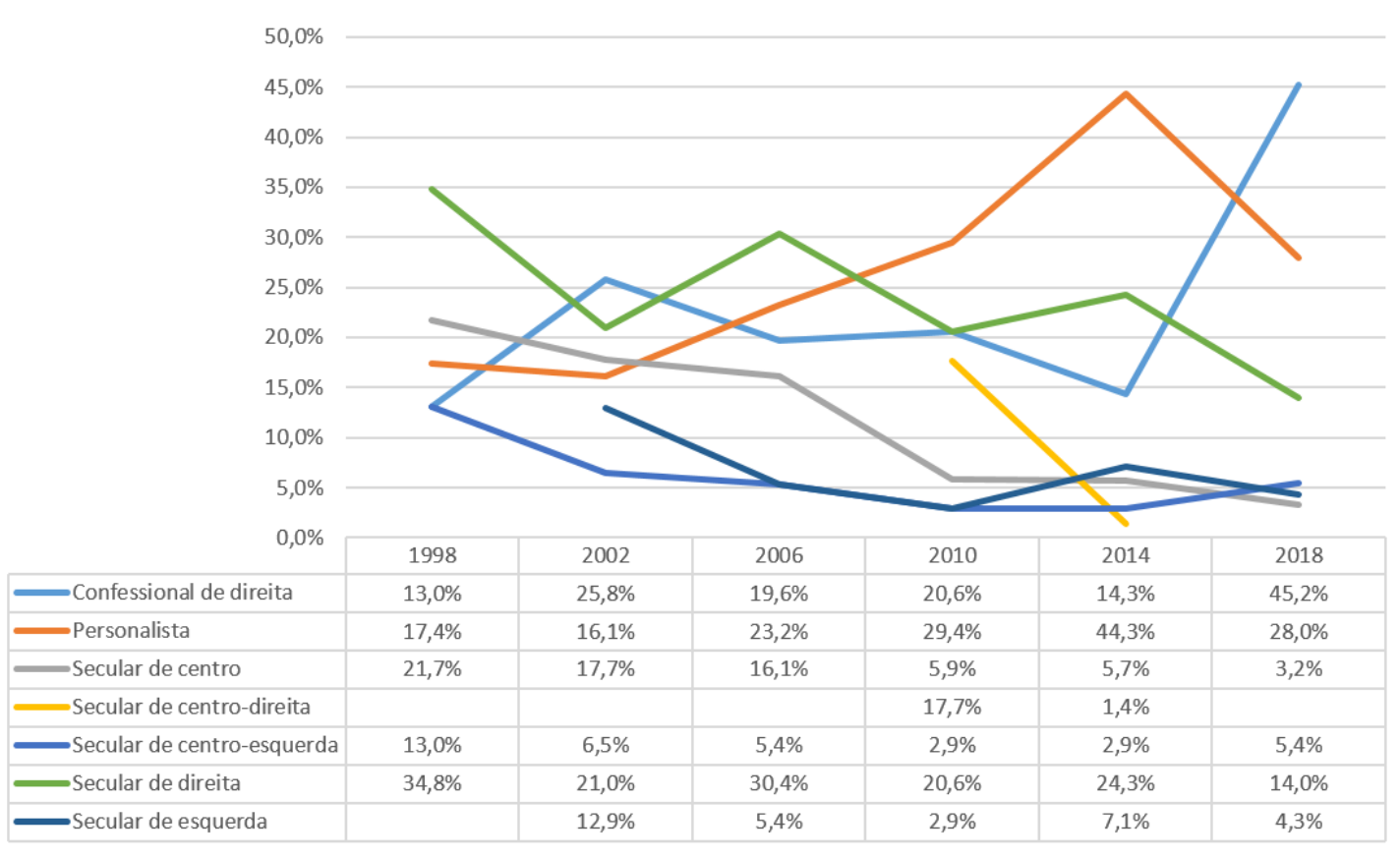

Fonte: Elaboração própria com base em Coppedge (1997), Codato et al. (2018) e TSE.

Os pastores do nosso recorte lançaram suas candidaturas a deputado federal por 45 siglas diferentes, resultado tanto da reconfiguração partidária (com mudanças de nomenclaturas e fusões de legendas) como da própria pulverização dos sacerdotes evangélicos pelas diversas agremiações em busca de votos. Apesar do grande número de legendas, o resultado mostrou que boa parte delas está concentrada em um mesmo núcleo ideológico, mais à direita, fisiológico e personalista. Partidos tradicionais de direita, como PFL/DEM e PP, receberam poucos nomes na média geral.

Também comparamos os dados eleitorais do TSE com as informações do Censo 2010 do IBGE sobre a distribuição dos evangélicos nas cinco regiões do país. Os números mostravam que a maior parte desse segmento estavam concentrados em três regiões: Norte, com 28,5\%; CentroOeste, com 26,8\%; e Sudeste, com 24,6\%. Portando, as regiões com a menor proporção de evangélicos no Brasil eram o Sul, com 20,2\%, e o Nordeste, com 16,4\%. Quanto aos candidatos, calculamos a porcentagem de pastores que usaram o status eclesiástico na urna em relação aos demais concorrentes.

Conforme o Gráfico 6, o resultado revelou que a região Norte além concentrar proporcionalmente a maior quantidade de evangélicos do país, também lidera em número de sacerdotes candidatos, com 1,2\%. Por sua vez, o Nordeste, região com a menor taxa de fiéis, ficou em segundo lugar, com 1,2\%. Em seguida aparecem Centro-Oeste, com 1,1\%; Sudeste, com 1\%; e Sul, com 0,9\%. Também verificamos o total de pastores pelas regiões. Neste caso, o Sudeste concentra a maior quantidade de nomes, com 43,3\%, bem à frente do Nordeste, com 24,7\%. Em seguida, o Norte aparece com 11,6\%, quase o mesmo índice que o Sul, com 11,1\%. O CentroOeste ocupa o último lugar, com 9,3\%. 
Gráfico 6 - Candidatos pastores por região (1998-2018)

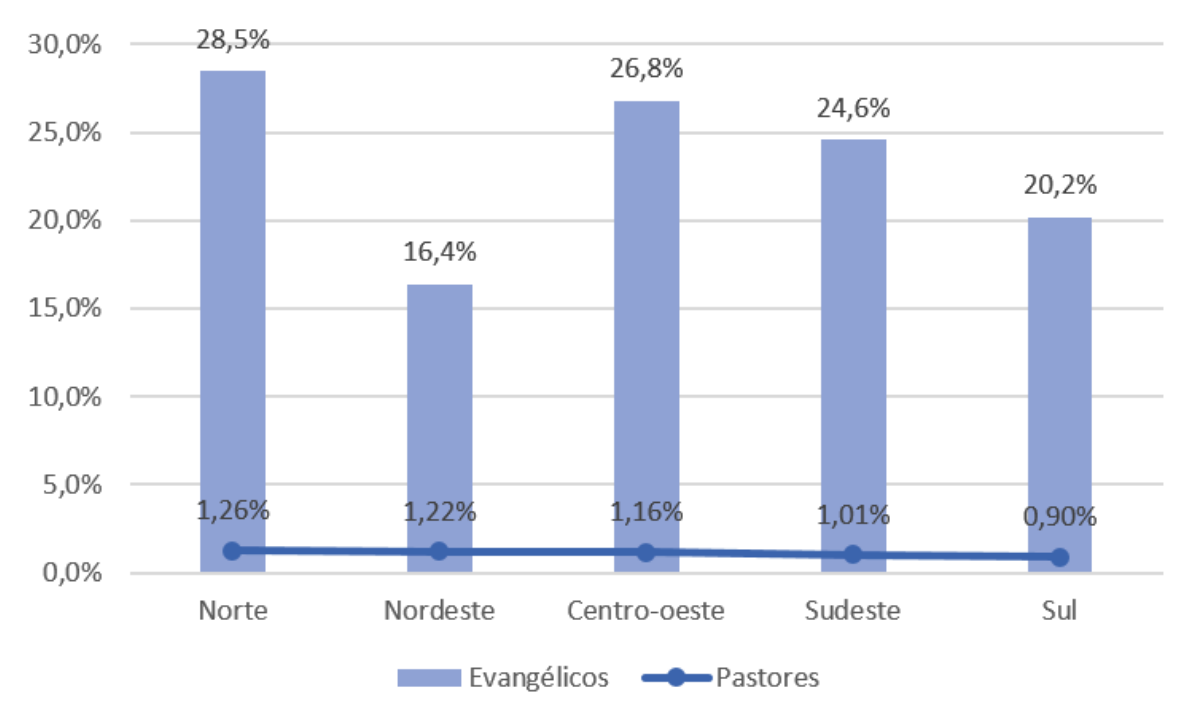

Fonte: Elaboração própria com base no Censo 2010/IBGE e TSE.

Embora São Paulo seja o estado com mais candidatos para o cargo de deputado federal, o Rio de Janeiro registrou a maior quantidade de concorrentes com o título de pastor na urna entre as seis eleições pesquisadas, com 16,8\% ante 12,5\%. Em terceiro, Minas Gerais registrou 10,1\% das candidaturas, seguido por Pernambuco, com 5,5\%; Bahia, com 5,2\%; Paraná, com 4,9\%; e Espírito Santo, com 3,8\%. Mesmo sendo um dos estados menos populosos do país, Roraima ocupa a oitava posição da lista, com 3,5\%, empatado com o Rio Grande do Sul, mas a frente de estados com mais vagas em disputa, como o Ceará, com 1,7\%; e Goiás, com 0,9\%.

\section{Considerações finais}

Este artigo buscou analisar o fenômeno das candidaturas evangélicas a partir do mapeamento dos pastores que utilizaram o título eclesiástico na urna eletrônica. Embora esse subgrupo represente $64,6 \%$ de todos os títulos religiosos usados e 70,4\% dos eleitos (GERARDI, 2016), ele ainda não havia sido estudado em detalhes pela literatura. Procuramos preencher essa lacuna ao observar seis eleições consecutivas, entre 1998 e 2018, para o cargo de deputado federal. O resultado apontou que, apesar de oscilações entre 2006 e 2010, esse movimento cresceu 291,6\% nas duas décadas, somando 344 candidaturas. Desde 2014, a curva é ascendente, saltado de 71 para 94 nomes em 2018, o maior patamar da série.

A nossa primeira hipótese contemplava o perfil social do segmento. O resultado esperado era de que o sacerdócio seria a principal ocupação declarada ao TSE e que os pastores não teriam ensino superior. Ao contrário do esperado, constatamos que $72,3 \%$ dos candidatos da nossa amostra exercem outras funções ou depende de outras fontes de renda. Um de cada 10 candidatos já ocupava algum cargo eletivo, o que reforça os achados de Gerardi (2016) de que possuir carreira política aumenta as chances de sucesso eleitoral desse grupo. Alguns deles também optaram por 
associar uma segunda ocupação ao nome de urna, como professor e militar. Já a expectativa sobre o grau de instrução foi confirmada. Ao todo, $68,5 \%$ dos pastores não possuíam ensino superior completo e dois deles declararam apenas saber ler e escrever.

Os resultados indicam que o sacerdócio nem sempre é visto como uma profissão e que exercer o trabalho pastoral não exige diploma, uma vez que o acesso à hierarquia eclesiástica não é elitizado em algumas denominações. Em relação ao gênero, as mulheres representaram apenas 10\% das candidaturas. Entre 1998 e 2018, foram 309 pastores e 35 pastoras. Contudo, verificamos uma leve tendência de alta nas últimas eleições, contrastando com a obrigatoriedade dos partidos de preencherem as cotas de candidaturas femininas nas eleições proporcionais. Todavia, embora as igrejas evangélicas permitam o sacerdócio de mulheres, as pastoras ainda ocupam pouco espaço nas listas partidárias para concorrer a uma vaga de deputada federal.

A nossa segunda hipótese contemplava a preferência partidária e esperava um predomínio das candidaturas de direita e a pulverização dos partidos, o que de fato se confirmou. Ao refinarmos a classificação, concluímos que o crescimento de pastores nas últimas eleições foi puxado principalmente pelos partidos confessionais, os pequenos de direita e os personalistas, que substituíram os grandes de direita e de centro. No grupo em declínio, as posições religiosas precisam se acomodar com a defesa de valores mais abstratos e liberais, o que tende a inibir os mais conservadores. Por sua vez, as pequenas legendas usam como estratégia lançar muitos candidatos para aumentar suas nominatas.

Os partidos de esquerda atraíram menos de $25 \%$ de pastores durante as duas décadas, mas com uma tendência de crescimento nas duas últimas eleições. Chama atenção o fato de o PT aparecer entre os últimos colocados da lista, com apenas $0,6 \%$ de nomes. O partido não atraiu sacerdotes mesmo durante o longo período em que governou o país. Entre as eleições de 2002 e 2010, quando estava eleitoralmente forte, nenhum sacerdote evangélico concorreu pela legenda usando o título religioso na urna.

Embora nosso foco tenha sido as candidaturas, também medimos o desempenho eleitoral. Apenas 8\% dos autodeclarados pastores foram eleitos entre 1998 e 2018, totalizando 30 vagas. A melhor safra foi em 2002, ano em que Lula se elegeu pela primeira vez, com 13 eleitos. Após um declínio entre 2006 e 2010, seis sacerdotes saíram vitoriosos em 2018. A eleição que também deu a vitória a Bolsonaro registrou o segundo melhor resultado da série. Cabe a ressalva que o número de candidatos nessa eleição foi 49\% maior que em 2002.

Acreditamos que uma das contribuições desta pesquisa foi explorar o nome de urna como um objeto de estudo da Ciência Política. Para Soares (2017), a escolha da identificação do candidato pode variar de acordo com os discursos que circulam na sociedade, atuando como um indicativo de mudanças do contexto social e do imaginário coletivo. Nesse sentido, o aumento do número de candidaturas com o título de pastor coincide com a ascensão dos evangélicos no Brasil nos mais variados estratos da sociedade. Na política, o crescimento da direita e do 
conservadorismo, sacramentada com a eleição de Bolsonaro, potencializou as iniciativas desse grupo de ocupar mais espaços no parlamento e nas instituições do Estado (SANTOS, 2020).

Este estudo também apresentou algumas limitações. Outros cargos eletivos poderiam ter sido analisados, incluindo também as esferas municipal e estadual. Algumas categorias, como faixa etária e gastos de campanha, também ficaram de fora. Mas acreditamos que o essencial foi contemplado considerando nossos objetivos e hipóteses. Além disso, pesquisas futuras poderão incluir os demais títulos eclesiásticos e a identificação das igrejas e denominações a que pertencem. O recorte pelo nome de urna também pode ser útil para estudar outras ocupações e segmentos sociais, além de articular-se com diferentes teorias e abordagens metodológicas.

\section{Referências}

ALVES, José Eustáquio et al. Distribuição espacial da transição religiosa no Brasil. Tempo Social, v. 29, n. 2, p. 215-242, 2017. Disponível em: https://www.scielo.br/scielo.php?pid=S0103-20702017000200215\&script=sci_arttext\&tlng=pt. Acesso em: 15 mai. 2021.

BERLATTO, Fábia; CODATO, Adriano; BOLOGNESI, Bruno. Da polícia à política: explicando o perfil dos candidatos das forças repressivas de Estado à Câmara dos Deputados. Revista Brasileira de Ciência Política, n. 21, p. 77-120, 2016.

BOAS, Taylor C. Pastor Paulo vs. Doctor Carlos : Professional Titles as Voting Heuristics in Brazil. Journal of Politics in Latin America, v. 2, p. 39-72, 2014. Disponível em: http://people.bu.edu/tboas/pastor_paulo.pdf. Acesso em: 15 mai. 2021.

BOHN, Simone R. Evangélicos no Brasil: perfil socioeconômico, afinidades ideológicas e determinantes do comportamento eleitoral. Opinião Pública, v. 10, n. 2, p. 288-338, 2004. Disponível em: https://www.scielo.br/scielo.php?script=sci_arttext\&pid=S010462762004000200006\&lng=pt\&tlng=pt. Acesso em: 15 mai. 2021.

BORGES, Tiago Daher Padovezi. Representação partidária e a presença dos evangélicos na política brasileira. 2007. Tese de Doutorado (Ciência Política). Universidade de São Paulo, São Paulo, 2017.

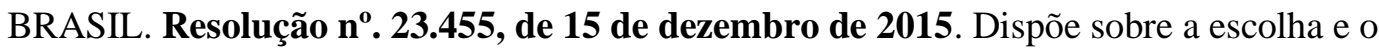
registro dos candidatos nas eleições de 2016. Brasília: Tribunal Superior Eleitoral, 2015. Disponível em: https://www.tse.jus.br/legislacao/compilada/res/2015/resolucao-no-23-455-de15-de-dezembro-de-2015. Acesso em: 15 mai. 2021.

CODATO, Adriano; BERLATTO, Fábia; BOLOGNESI, Bruno. Tipologia dos políticos de direita no Brasil. Análise Social, v. 53, n. 229 (4), p. 870-897, 2018. Disponível em: https://www.jstor.org/stable/26589933?seq=1. Acesso em: 15 mai. 2021.

CAMPOS, Leonildo Silveira. Os políticos de Cristo: uma análise do comportamento político de protestantes históricos e pentecostais no Brasil. In: BURITY, Joanildo; MACHADO, Maria das Dores (org.). Os votos de Deus: evangélicos, política e eleições no Brasil. Recife:

Massangana, 2006, p. 29-89.

COPPEDGE, Michael. A classification of Latin American political parties. Working Paper $\mathrm{n}^{\circ}$ 244, Kellog Institute, 1997.

DUVERGER, Maurice. Os Partidos Politicos. Brasília: Editora UnB, 1980.

FERNANDES, Rubem César. Novo nascimento: Os evangélicos em casa, na igreja e na política. Rio de Janeiro: Mauad Editora, 1998. 
FONSECA, Alexandre Brasil. Surge uma nova força política: A Igreja Universal do Reino de Deus nas eleições de 1994. Rio de Janeiro, 1996. Mimeografado.

FRESTON, Paul. "Neo-pentecostalism" in Brazil: Problems of Definition and the Struggle for Hegemony. Archives de sciences sociales des religions, p. 145-162, 1999. Disponível em: https://www.jstor.org/stable/30117006?seq=1. Acesso em: 15 mai. 2021.

FRESTON, Paul. Evangelical christianity and democracy in Latin America. London: Oxford University Press, 2008.

GERARDI, Dirceu André. Parlamentares evangélicos no Brasil: perfil de candidatos e eleitos a deputado federal (1998-2014). Observatório de Elites Políticas e Sociais do Brasil, v. 3, n. 14, p. 1-18, 2016. Disponível em: https://www.researchgate.net/profile/DirceuGerardi/publication/330397446. Acesso em: 15 mai. 2021.

GONÇALVES, Rafael Bruno. Bancada evangélica?: uma análise do discurso parlamentar evangélico durante a 52 ${ }^{\mathbf{a}}$ Legislatura da Câmara Federal. 2011. Dissertação de Mestrado (Ciência Política). Universidade Federal de Pelotas, Pelotas, 2011. Disponível em: http://repositorio.ufpel.edu.br:8080/handle/123456789/1591. Acesso em: 15 mai. 2021.

KIRCHHEIMER, Otto. A transformação dos sistemas partidários da Europa Ocidental. Revista Brasileira de Ciência Política, n. 7, 2012, p. 349-385. Disponível em: https://www.scielo.br/scielo.php?pid=S0103-33522012000100014\&script=sci_arttext\&tlng=pt. Acesso em: 15 mai. 2021.

LACERDA, Fabio. Evangelicals, pentecostals and political representation in Brazilian legislative elections (1998-2010). Revista Brasileira de Ciências Sociais, v. 32, n. 93, 2017. Disponível em: https://www.scielo.br/scielo.php?pid=S010269092017000100508\&script=sci_arttext. Acesso em: 15 mai. 2021.

MALFATTI, Selvino Antonio. A democracia cristã como opção aos totalitarismos europeus. Revista Estudos Filosóficos, n. 9, 2017. Disponível em: http://www.seer.ufsj.edu.br/index.php/estudosfilosoficos/article/view/2205. Acesso em: 15 mai. 2021.

MARIANO, Ricardo. Expansão pentecostal no Brasil: o caso da Igreja Universal. Estudos avançados, v. 18, n. 52, p. 121-138, 2004. Disponível em: https://www.scielo.br/scielo.php?pid=S0103-40142004000300010\&script=sci_arttext. Acesso em: 15 mai. 2021.

MACHADO, Maria das Dores Campos. Pentecostais, sexualidade e família no Congresso Nacional. Horizontes Antropológicos, n. 47, p. 351-380, 2017. Disponível em: https://journals.openedition.org/horizontes/1529. Acesso em: 15 mai. 2021.

ORO, Ari Pedro. A política da Igreja Universal e seus reflexos nos campos religioso e político brasileiros. Revista Brasileira de Ciências Sociais, v. 18, n. 53, p. 53-69, 2003. Disponível em: https://www.scielo.br/pdf/rbcsoc/v18n53/18078. Acesso em: 15 mai. 2021.

PANEBIANCO, Angelo. Organização e poder nos partidos políticos. São Paulo: Martins Fontes, 2005.

PRANDI, Reginaldo; SANTOS, Renan William. Quem tem medo da bancada evangélica? Posições sobre moralidade e política no eleitorado brasileiro, no Congresso Nacional e na Frente Parlamentar Evangélica. Tempo Social, v. 29, n. 2, p. 187, 2017. Disponível em: https://www.scielo.br/scielo.php?script=sci_arttext\&pid=S0103-

20702017000200187\&lng=en\&nrm=iso\&tlng=pt. Acesso em: 15 mai. 2021.

QUADROS, Marcos Paulo dos Reis; MADEIRA, Rafael Machado. Fim da direita envergonhada? Atuação da bancada evangélica e da bancada da bala e os caminhos da representação do conservadorismo no Brasil. Opinião Pública, v. 24, n. 3, p. 486-522, 2018. Disponível em: https://www.scielo.br/scielo.php?pid=S0104-

62762018000300486\&script=sci_arttext. Acesso em: 15 mai. 2021. 
SANTOS, Andreza Marcião; ROCHA, Shirlene Aparecida. Antroponímia e Ciência Política: uma possível relação entre os nomes de urna e o voto. RE-UNIR - Revista do Centro de Estudos da Linguagem da Fundação Universidade Federal de Rondônia, v. 6, n. 2, 2020.

SANTOS, Rayani Mariano. A mobilização de questões de gênero e sexualidade e o fortalecimento da direita no Brasil. Agenda Política, v. 8, n. 1, p. 50-77, 2020. Disponível em: https://www.agendapolitica.ufscar.br/index.php/agendapolitica/article/view/308. Acesso em: 15 mai. 2021.

SILVA, Fabio Lacerda. Apóstolos, Bispos e Pastores: as candidaturas evangélicas para o legislativo no Brasil (1998-2014). V Seminário Discente do Programa de Pós-Graduação em Ciências Política da USP, São Paulo, SP, 2015.

SILVA, Hélerson. Os novos atores "evangélicos" e a conquista do espaço público na América Latina. Reflexão, v. 43, n. 2, p. 243-263, 2019. Disponível em: https://seer.sis.puccampinas.edu.br/seer/index.php/reflexao/article/view/4377. Acesso em: 15 mai. 2021.

SILVA, Victor Augusto Araújo. Grupos suprapartidários no Congresso brasileiro: uma análise da Frente Parlamentar Evangélica. Revista Três Pontos, v. 9, n. 2, 2012, p. 27-36. Disponível em: https://periodicos.ufmg.br/index.php/revistatrespontos/article/view/3171. Acesso em: 15 mai. 2021.

SOARES, Paola Santos Lima. O aumento da inclusão de postos e graduações militares em nomes de urna como um indicador de mudanças no imaginário social brasileiro. Revista GTLex, v. 3, n. 1, p. 169-182, 2017. Disponível em: http://www.seer.ufu.br/index.php/GTLex/article/view/50758. Acesso em: 15 mai. 2021.

Artigo recebido em: 2021-03-05

Artigo reapresentado em: 2021-04-06

Artigo aceito em: 2021-04-22 